\title{
Wstępna charakterystyka geochemiczna amfibolitów i skał ultramaficznych terranu West Ny-Friesland, pólnocny Spitsbergen
}

\author{
Jakub Bazarnik ${ }^{1}$, Abigail Barker², Jarosław Majka ${ }^{2,3}$, Karolina Kośmińska ${ }^{3}$, \\ Synnøve Elvevold ${ }^{4}$, Mirosława Bazarnik ${ }^{5}$
}

Preliminary geochemical characteristics of amphibolites and ultramafic rocks of the West Ny-Friesland Terrane, Northern Spitsbergen. Prz. Geol., 69: 406-410; doi: 10.7306/2021.24

A b s tra c t. The metamorphic Atomfjella Complex of the West Ny-Friesland Terrane, which belongs to the Eastern Basement Svalbard Province, is composed of four nappes, namely Dirksodden, Nordbreen, Rekvika and Finlandveggen. All these nappes comprise a granitic gneiss basement associated with a metasedimentary cover, both cut by numerous mafic dykes. At the top of the Atomfjella Complex, close to the boundary with the Mosselhalvøya Group (Nordaustlandet terrane), the lenses of ultramafic rocks also occur. Some authors suggested that they provide evidence for the presence of a deeply rooted, large-scale tectonic boundary between the West $\mathrm{Ny}$-Friesland and Nordaustlandet terranes.

The performed geochemical characterization of amphibolites and ultramafic rocks showed that nearly all major elements (except Si and $\mathrm{Fe}$ ) as well as LILE, have wide compositional ranges and no obvious trends (Bazarnik, Majka, 2021). It is conceivable that the Caledonian metamorphism may have affected $\mathrm{K}, \mathrm{Na}$ and $\mathrm{P}$, as well as LILE, and caused scatter of Al, Ti, Ca and Fe, and likely Si. The trace and REE elements plots are characterized mainly by trends that probably express the original magmatic processes. However, the elements that clearly deviate from these trends are disturbed due to either metamorphism or crustal assimilation. According to the $\mathrm{Th} / \mathrm{Yb}$ vs $\mathrm{Nb} / \mathrm{Yb}$ relationship, the studied rocks indicate generally low influence of crustal contamination, with only 3 samples in the field of MORB-OIB array (Fig. 4B). Besides the higher content of $\mathrm{Mg}$ and some other minor differences in chemical composition, the ultramafic rocks exhibit trends similar to that of amphibolites.

Based on this aforementioned similarity and the confirmed influence of the Caledonian metamorphism on both groups of rocks, we speculate about the common history of both groups of rocks. Moreover, thanks to the identification of metamorphic alterations in ultramafic rocks, it was proved that these rocks must be pre-Caledonian and, in turn, older than the alleged terrane boundary. Thus, the ultramafic bodies located close to the top of the Atomfjella Complex cannot mark the large terrane boundary and do not provide any evidence of a deeply rooted tectonic zone, but merely the result of ascension from deeper levels of the mantle.

Keywords: amphibolites, ultramafites, West Ny-Friesland terrane, Svalbard

W celu doprecyzowania informacji o pochodzeniu maficznych dajek oraz ciał ultramaficznych należących do kompleksu Atomfjella w terranie West Ny-Friesland na północy Spitsbergenu i zweryfikowania, czy mogły być zasilane z tego samego źródła magmowego, porównano ich skład chemiczny. Ze względu na usytuowanie skał ultramaficznych tuż poniżej domniemanego nasunięcia Mosselhalvøya uważa się, że mogą być one powiązane z głęboką strefą tektoniczną, stanowiącą granice pomiędzy terranami West Ny-Friesland i Nordaustlandet, należącymi do wschodniej prowincji kaledońskiego podłoża Svalbardu (Witt-Nilson i in., 1998; Gee, Tebenkov, 2004). Kompleksowa analiza składu chemicznego tych skał umożliwiła określenie ich genezy. Uzyskane dane mogą się przyczynić do lepszego rozpoznania przebiegu granic terranów w północnej części Spitsbergenu oraz lokalnej tektonostratygrafii. W artykule przedstawiono wstępną ewaluację wyników korelacji zmetamorfizowanych skał maficznych i ultramaficznych odsłaniających się w obrębie jednego kompleksu tektonicznego.

\section{BUDOWA GEOLOGICZNA}

Kaledońskie podłoże krystaliczne archipelagu Svalbardu jest zwyczajowo dzielone na trzy główne prowincje tektoniczne: północno-zachodnią, południowo-zachodnią i wschodnią (Gee, Tebenkov, 2004; Dallmann i in., 2015). Są one rozdzielone wielkoskalowymi, przesuwczymi strefami uskokowymi (np. Gee, Tebenkov, 2004; Mazur i in., 2009; Michalski i in., 2012; Bazarnik i in., 2019b; Faehnrich i in., 2020; ryc. 1). W skałach podłoża Svalbardu stwierdzono liczne przedkaledońskie (archaiczne, paleoproterozoiczne, mezoproterozoiczne i neoproterozoiczne) zdarzenia metamorficzne i magmowe (patrz np. Dallmann i in., 2015), jednak dominuje w nich młodsza więźba kaledońska (np. Harland, 1985; Majka, Kośmińska, 2017). Wschodnia prowincja krystalicznego podłoża Svalbardu jest oddzielona od pozostałych dwóch prowincji regionalną strefą przesuwczą Billefjorden (np. Gee, Tebenkov, 2004; Michalski i in., 2012), natomiast granica prowincji południowo-zachodniej i północno-zachodniej jest wyznaczona przez młodszy front, tzw. West Spitsbergen fold and thrust belt (Harland, Horsfield, 1974; Dallmann i in., 1993).

Do wschodniej prowincji podłoża krystalicznego należą dwa subterrany: Nordaustlandet i West Ny-Friesland. Terran Nordaustlandet składa się z neoproterozoicznych skał magmowych wieku ok. 975-970 Ma (McClelland i in., 2019), intrudujących w późnomezoproterozoiczne lub też wczesnoneoproterozoiczne skały terygeniczne.

\footnotetext{
${ }^{1}$ Państwowy Instytut Geologiczny - Państwowy Instytut Badawczy, Oddział Karpacki, ul. Skrzatów 1, 31-560 Kraków; Jakub.Bazarnik@pgi.gov.pl

${ }^{2}$ Department of Earth Sciences, Uppsala University, Villavägen 16, 75236 Uppsala, Sweden

${ }^{3}$ Wydział Geologii, Geofizyki i Ochrony Środowiska, Akademia Górniczo-Hutnicza, al. Mickiewicza 30, $30-059$ Kraków

${ }^{4}$ Norwegian Polar Institute, Framsenteret, Hjalmar Johansens gate 14, 9296, Tromsø, Norway

${ }^{5}$ Wydział Inżynieri Lądowej, Politechnika Krakowska, ul. Warszawska 24, 31-155 Kraków
} 


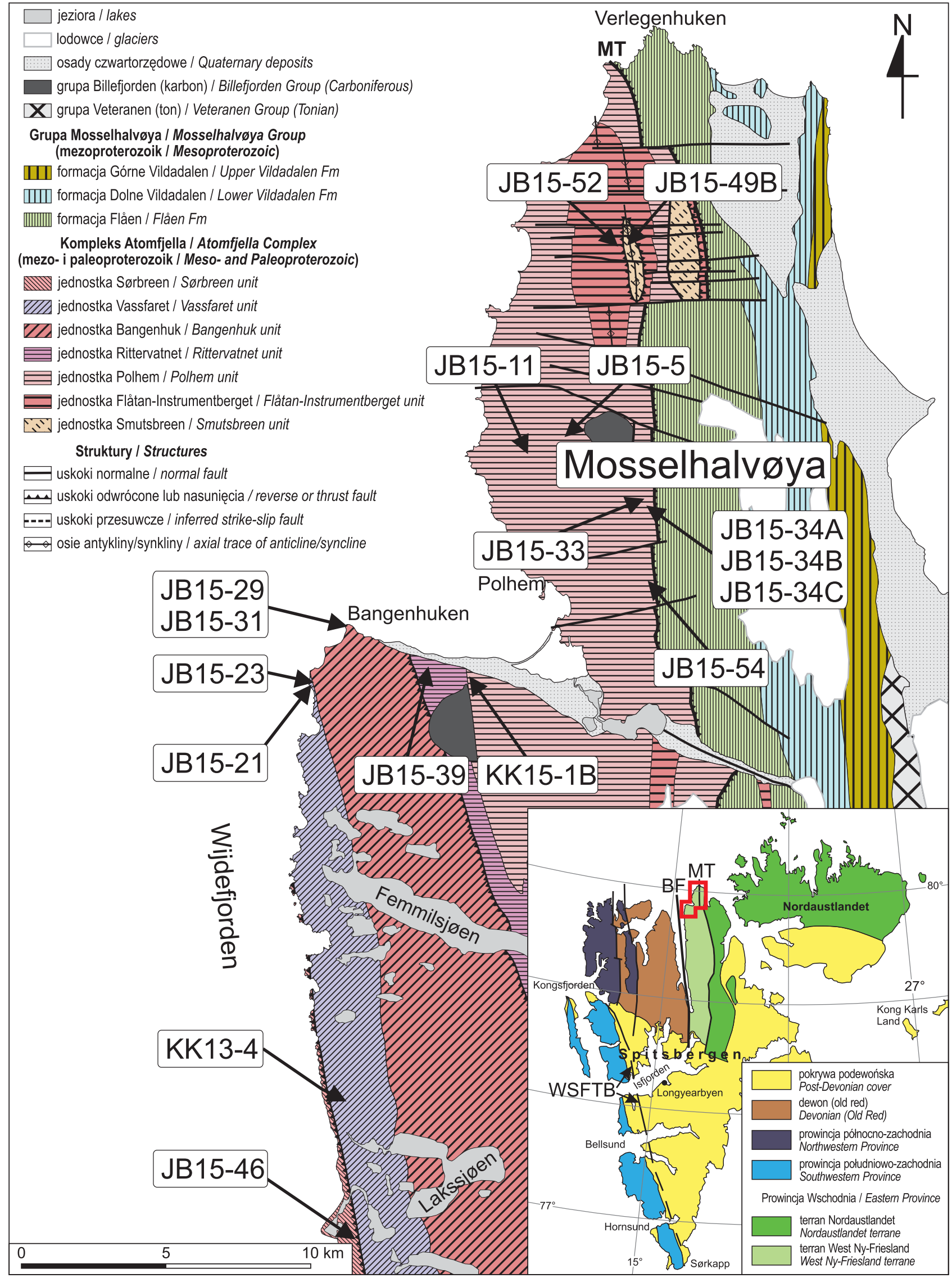

Ryc. 1. Mapa geologiczna północnej części półwyspu Ny-Friesland (wg Elvevold, Dallman, 2011, uproszczona): MT - nasunięcie Mosselhalvøya. W dolnym prawym rogu: schematyczna mapa geologiczna archipelagu Svalbard (wg Gee, Tebenkov, 2004, zmodyfikowana): BF - strefa uskokowa Billefjorden, WSFTB - front tzw. West Spitsbergen Fold and Thrust Belt

Fig. 1. Geological map of northern part of Ny-Friesland peninsula (after Elvevold and Dallmann, 2011, simplified): MT - Mosselhalvøya Thrust. Bottom right corner: schematic geological map of the Svalbard Archipelago (modified from Gee and Tebenkov, 2004): BF - Billefjorden Fault Zone, WSFTB - West Spitsbergen Fold and Thrust Belt 
Tab. 1. Tektonostratygrafia północnego Ny-Friesland (wg Witt-Nilsson i in., 1998, zmieniona)

Table 1. Northern Ny-Friesland tectonostratigraphy (after Witt-Nilsson et al., 1998, modified)

\begin{tabular}{|c|c|}
\hline \multicolumn{2}{|c|}{ Nasunięcie Mosselhalvøya / Mosselhalvøya Nappe } \\
\hline grupa Mosselhalvøya / Mosselhalvøya Group & lupki granatowe, kwarcyty, fyllity / garnet schists, quartzites, phyllites \\
\hline \multicolumn{2}{|l|}{ Nasunięcie Dirksodden / Dirksodden Nappe } \\
\hline jednostka Sørbreen / Sørbreen unit & kwarcyty i amfibolity / quartzites and amphibolites \\
\hline jednostka Dirkslaguna / Dirkslaguna unit & $\begin{array}{l}\text { zmylonityzowane metagranity / mylonitic metagranitoids } \\
\text { (ca. } 1750 \mathrm{Ma} \text {, vide Hellman i in., 2001) }\end{array}$ \\
\hline \multicolumn{2}{|l|}{ Nasunięcie Nordbreen / Nordbreen Nappe } \\
\hline jednostka Vassfaret / Vassfaret unit & semipelity i amfibolity / semipelites and amphibolites \\
\hline kompleks Bangenhuk / Bangenhuk unit & $\begin{array}{l}\text { gnejsy granitowe i metatufy / granitic gneisses and metatuffs } \\
\text { (ca. 1760-1750 Ma, Johansson i in., 1995, Bazarnik i in., 2019a) }\end{array}$ \\
\hline \multicolumn{2}{|l|}{ Nasunięcie Rekvika / Rekvika Nappe } \\
\hline jednostka Rittervatnet / Rittervatnet unit & kwarcyty, metapelity, margle i amfibolity / quartzites, metapelites, marls and amphibolites \\
\hline jednostka Polhem / Polhem unit & kwarcyty, amfibolity i konglomeraty / quartzites, amphibolites and conglomerates \\
\hline $\begin{array}{l}\text { jednostka Instrumentberget-Flåtan } \\
\text { Instrumentberget-Flåtan unit }\end{array}$ & $\begin{array}{l}\text { gnejsy granitowe / granitic gneisses } \\
\text { (ca. 1740 Ma, Hellman i in., 1997) }\end{array}$ \\
\hline \multicolumn{2}{|c|}{ Nasunięcie Finlandveggen / Finlandveggen Nappe } \\
\hline jednostka Smutsbreen / Smutsbreen unit & łupki granatowe, margle i amfibolity / garnet schists, marls and amphibolites \\
\hline jednostka Eskolabreen / Eskolabreen unit & $\begin{array}{l}\text { zmylonityzowane gnejsy granitoidowe / mylonitic granitic gneisses } \\
\text { (ca. } 1750 \text { Ma, Johansson, Gee, 1999) }\end{array}$ \\
\hline
\end{tabular}

Te prekambryjskie utwory są przykryte skałami osadowymi o wieku od tonu do ordowiku. W zachodniej części tego terranu odsłaniają się także skały metamorficzne grupy Mosselhalvøya o protolicie prekambryjskim (Bazarnik i in., 2019a), stanowiące najniższą jednostkę tektonostratygraficzną terranu Nordaustlandet w północnej części półwyspu Ny-Friesland (Gee, Tebenkov, 2004). Jednostki tej grupy są nasunięte na skały kompleksu Atomfjella, należącego do terranu West Ny-Friesland. Skały kompleksu Atomfjella tworzą antyklinę o długości ok. $150 \mathrm{~km}$ o osi północ-południe (Witt-Nilsson i in., 1998), składającą się z czterech nasunięć: Dirksodden, Nordbreen, Rekvika i Finlandveggen (ryc. 1, tab. 1). Wszystkie cztery nasunięcia mają podobną budowę - paleoproterozoiczne podłoże, uformowane $\mathrm{z}$ granitowych gnejsów i tufitów wieku ok. 1760-1740 Ma (Johansson i in., 1995; Hellman i in., 1997, 2001; Johansson, Gee, 1999; Bazarnik i in., 2019b), jest przykryte zmetamorfizowanymi skałami osadowymi. Zarówno podłoże magmowe, jak i seria osadowa są poprzecinane licznymi maficznymi dajkami (ryc. 2 - patrz str. 396). Stosując datowania U-Pb cyrkonów, wiek jednej z dajek gabrowych w jednostce Bangenhuk (nasunięcie Nordbreen) oznaczono na ok. 1380 Ma, (Bazarnik i in., 2019b), jednakże wiek większości dajek amfibolitowych pozostaje nadal nieznany. Ponadto w nasunięciu Rekvika stwierdzono obecność licznych soczewek skał ultramaficznych (ryc. 3 - patrz str. 396) występujących wzdłuż granicy z grupą Mosselhalvøya. Ich obecność, interpretowana jako wynik wynoszenia tych skał z dużych głębokości, jest uznawana przez niektórych autorów (Witt-Nilson i in.,1998; Gee, Tebenkov, 2004) za przesłankę decydującą o tym, że kontakt między kompleksem Atomfjella a grupą Mosselhalvøya stanowi główną granicę między terranami. Wart odnotowania jest jednak fakt, że ultramafity tworzą ciała równoległe do innych dajek maficznych, ponadto występują jedynie w obrębie kompleksu skał Atomfjella, a nie w samej strefie nasunięcia.

\section{METODYKA BADAŃ}

Próbki amfibolitów i ultramafitów kompleksu Atomfjella (ryc. 1) pobrano podczas międzynarodowych warsz- tatów SvalGeoBase 2013 oraz ekspedycji naukowej Circum Arctic Structural Events (CASE 18 - Mosselbukta 2015), zorganizowanej przez Federal Institute for Geosciences and Natural Resources, Niemcy.

Obserwacje petrograficzne prowadzono pod mikroskopem optycznym oraz $\mathrm{z}$ zastosowaniem mikrosondy elektronowej Cameca SX100 w Laboratorium Analiz w Mikroobszarze Państwowego Instytutu Geologicznego Państwowego Instytutu Badawczego. Oznaczenia składu chemicznego skał (tzw. bulk rock) wykonano w zewnętrznym, atestowanym laboratorium Bureau Veritas Mineral Laboratories. Rozdrobnione i sproszkowane próbki stopiono $\mathrm{z} \mathrm{LiBO}_{2} / \mathrm{Li}_{2} \mathrm{~B}_{4} \mathrm{O}_{7}$, a następnie rozpuszczono w kwasie azotowym o wysokiej czystości. Skład chemiczny oznaczono za pomocą spektrometrów ICP-OES i ICP-MS. Wyniki analiz składu chemicznego umieszczono w bazie danych Open Science Framework (Bazarnik, Majka, 2021).

\section{WYNIKI I DYSKUSJA}

Skład chemiczny badanych ultramafitów terranu West Ny-Friesland odpowiada skałom magmowym zlokalizowanym na diagramie TAS w polu pikrobazaltów (ryc. 4A), a skład większości amfibolitów - bazaltom, co potwierdziły wyniki obserwacji petrograficznych. W polu bazaltów plasuje się także próbka metagabra o znanym wieku ok. 1380 Ma (Bazarnik i in., 2019b). Dwie próbki z nasunięcia Nordbreen odpowiadają trachybazaltowi i trachyandezytowi, natomiast dwie próbki $\mathrm{z}$ nasunięcia Rekvika zaklasyfikowano jako foidyt i bazalt andezytowy (ryc. 4A).

Wyniki oznaczeń zawartości większości pierwiastków głównych, zarówno w skałach ultramaficznych, jak i amfibolitach, są znacznie rozproszone - na wykresach nie stwierdzono wyraźnie zarysowanych linii trendów (Bazarnik, Majka, 2021). Jedynie na wykresach zawartości Si i Fe zaznaczają się słabe linie trendów (Bazarnik, Majka, 2021), zaburzone jednak przez pojedyncze odmienne wyniki, które mogą być skutkiem metamorfizmu. Pod wpływem kaledońskich procesów metamorficznych zmianie uległa zawartość $\mathrm{K}$, Na i $\mathrm{P}$ w badanych skałach, co powoduje wyraźne rozproszenie punktów na wykresach Al, Ti, Ca i Fe, a w przy- 
padku próbki z nasunięcia Rekvika najprawdopodobniej także na wykresie Si. Zestawienie oznaczeń głównych pierwiastków pokazuje również, że ultramafity zawierają znacznie więcej Mg (Bazarnik, Majka, 2021). Pozostałe pierwiastki główne w ultramafitach wykazują takie same trendy (lub ich brak) jak w amfibolitach.
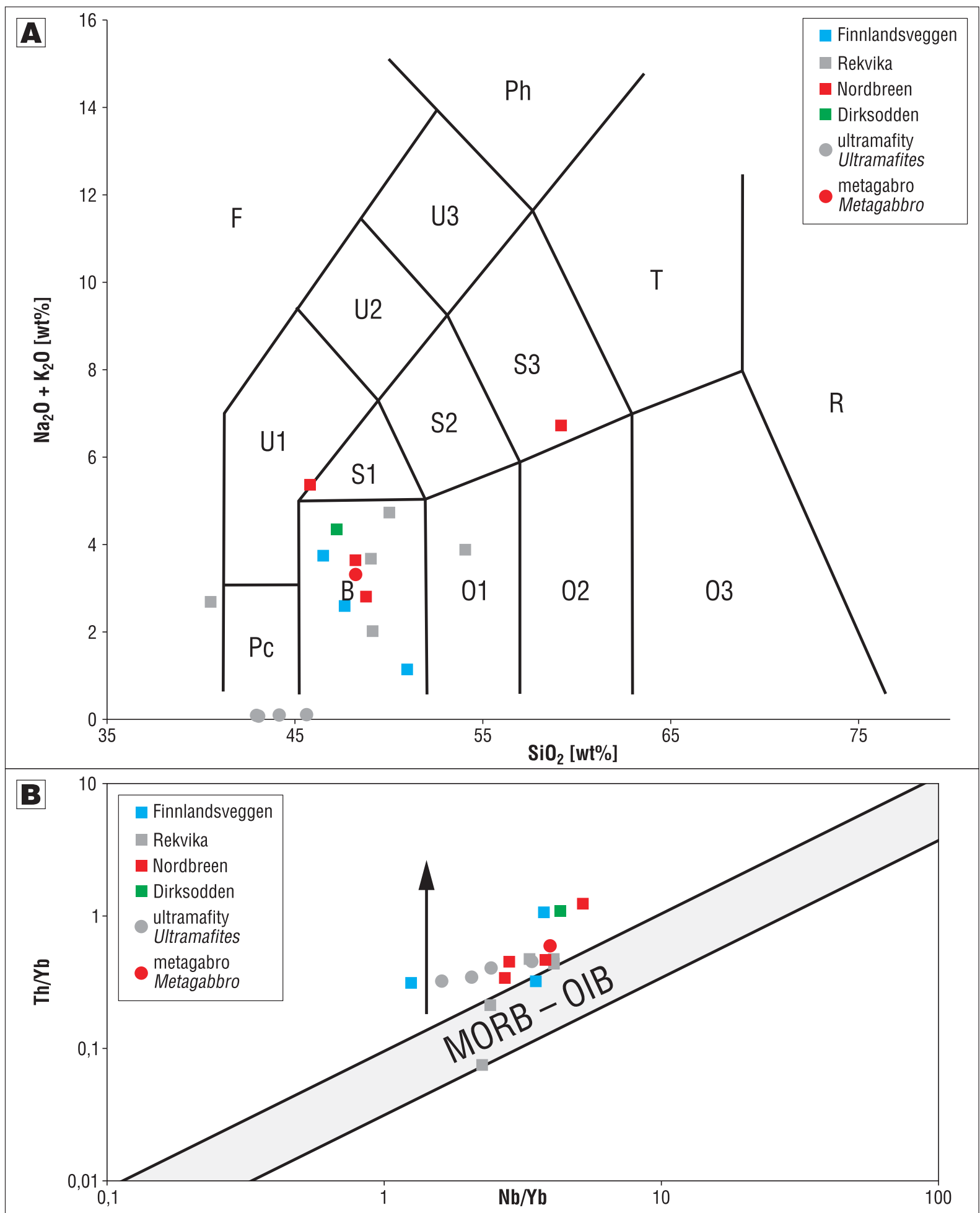

Ryc. 4. A - Diagram TAS (total-alkali silica) z zaznaczonymi próbkami amfibolitów i ultramafitów: $\mathbf{F}$ - foidyt, Pc - pikrobazalt, B - bazalt, $\mathbf{O 1}$ - bazaltowy andezyt, $\mathbf{O 2}$ - andezyt, $\mathbf{O 3}$ - dacyt, $\mathbf{R}$ - ryolit, S1 - trachybazalt, S2 - bazaltowy trachyandezyt, S3 - trachyandezyt, T - trachit, U1 - bazanit i tefryt, U2 - fenotefryt, $\mathbf{U 3}$ - tefryfonolit, $\mathbf{P h}$ - fonolit. B - Wykres Th/Yb $\mathrm{Nb} / Y b$ wskazujący wpływ kontaminacji skorupą ziemską (kierunek strzałki) analizowanych próbek: MORB - mid-ocean ridge basalts (bazalty grzbietów śródoceanicznych), OIB - ocean island basalts (bazalty wysp oceanicznych)

Fig. 4. A - Total-alkali silica (TAS) diagram of analysed amphibolites and ultramafites samples: F - foidite, Pc - picrobasalt, $\mathbf{B}$ - basalt, $\mathbf{O 1}$ - basaltic andesite, $\mathbf{O 2}$ - andesite, $\mathbf{O 3}$ - dacite, $\mathbf{R}$ - rhyolite, $\mathbf{S 1}$ - trachybasalt, $\mathbf{S 2}$ - basaltic trachyandesite, $\mathbf{S 3}$ - trachyandesite, $\mathbf{T}$ - trachyte, $\mathbf{U} \mathbf{1}$ - basanite and tephrite, $\mathbf{U} 2$ - phonotephrite, $\mathbf{U} 3$ - tephriphonolite, $\mathbf{P h}$ - phonolite. $\mathbf{B}$ - Th/Yb $\mathrm{Nb} / \mathrm{Yb}$ plot indicates crustal contamination (arrow) for all analysed samples: MORB - mid-ocean ridge basalts, OIB - ocean island basalts 
Koncentracja pierwiastków śladowych i REE w badanych skałach ultramaficznych jest podobna do obserwowanej w amfibolitach. Na wykresach odzwierciedlających zawartość dużych jonów litofilnych (tzw. LILE) w obu analizowanych typach skał nie zaznaczają się widoczne linie trendów (Bazarnik, Majka, 2021). Natomiast rozproszenie $\mathrm{Sr}, \mathrm{Ba}, \mathrm{Rb}$ i Th najprawdopodobniej zostało spowodowane przez metamorfizm (Bazarnik, Majka, 2021). Bardzo wyraźne i wspólne dla skał ultramaficznych i amfibolitów linie trendów są widoczne na wykresach pierwiastków śladowych, m.in. La, Nd, Sm i Nb (Bazarnik, Majka, 2021). Wyniki te odzwierciedlają prawdopodobnie procesy magmowe. Jednak skład chemiczny części próbek wyraźnie różni się od zobrazowanego przez linie trendów. Przypuszcza się, że zróżnicowanie to nastąpiło pod wpływem metamorfizmu albo na skutek asymilacji skorupy ziemskiej podczas intrudowania magmy.

Wszystkie próbki skał ultramaficznych oraz znakomita większość amfibolitów nie są spilityzowane, tj. impregnowane sodem (Bazarnik, Majka, 2021). Jedynie w czterech próbkach amfibolitów stwierdzono podwyższoną zawartość Na, Ba i Sr, która może świadczyć o przebiegu tego procesu. Na podstawie wykresu stosunków $\mathrm{Th} / \mathrm{Nb}$ vs $\mathrm{La} / \mathrm{Nb}$ (ryc. 4B) stwierdzono, że kontaminacja magmy przez wchłanianie skorupy ziemskiej miała niewielki wpływ na skład chemiczny większości badanych próbek, tylko trzy z nich lokują się w polu charakterystycznym dla MORB-OIB.

Reasumując, na podstawie analizy składu chemicznego amfibolitów i skał ultramaficznych wykazano wyraźne podobieństwo tych skał pod względem zawartości analizowanych pierwiastków oraz wpływ kaledońskiego metamorfizmu na obie grupy skał. Dzięki potwierdzeniu obecności śladów procesów metamorficznych w skałach ultramaficznych udowodniono, że skały te muszą być przedkaledońskie, czyli starsze od domniemanej granicy terranów. A zatem ciała ultramafitów zlokalizowane w stropie kompleksu Atomfjella nie mogą wyznaczać granicy terranu i nie są dowodem na istnienie potężnego rozłamu tektonicznego, a jedynie efektem wynurzania z głębszych poziomów płaszcza.

\section{WNIOSKI}

1) Skład chemiczny badanych próbek amfibolitów i skał ultramaficznych terranu West Ny-Friesland (północny Spitsbergen) jest zbliżony do bazaltów.

2) Stwierdzono, że kontaminacja magmy przez skorupe ziemską oraz spilityzacja odegrały niewielką rolę w przeobrażaniu tych skał.

3) Analiza składu chemicznego pierwiastków głównych, śladowych i REE badanych skał ultramaficznych i amfibolitów, pomimo ujawnienia niewielkich różnic, dowiodła, że wykazują one podobne trendy, co stanowi przesłankę ich wspólnej historii.

4) $\mathrm{Na}$ podstawie identyfikacji w skałach ultramaficznych kaledońskich procesów metamorficznych udowodniono, że są one przedkaledońskie, a więc starsze od domniemanej granicy terranów. Ciała ultramaficzne znajdujące się w górnej części profilu kompleksu Atomfjella nie mogą zatem wyznaczać granicy terranów i nie stanowią dowodu na istnienie głęboko zakorzenionej strefy tektonicznej.

Autorzy dziękują Recenzentom: prof. dr hab. Katarzynie Jarmołowicz-Szulc oraz prof. dr hab. Jerzemu Nawrockiemu za cenne i konstruktywne uwagi, które przyczyniły się do uzyskania ostatecznej wersji artykułu. Badania realizowano w ramach grantu NCN nr 2015/19/N/ST10/02646. Prace terenowe J. Bazarnika w 2015 r. zostały cześciowo sfinansowane przez grant Svalbard Science Forum 246130 (RiS ID 10101) we współpracy z Norweskim Instytutem Polarnym.

\section{LITERATURA}

BAZARNIK J., MAJKA J., MCCLELLAND W.C., KOŚMIŃSKA K., PIEPJOHN K., ELVEVOLD S., STRAUSS J.V. 2019a - Is the Mosselhalvøya thrust a major boundary between West Ny-Friesland and Nordaustlandet terranes of the Svalbard Caledonides? T13G-0262, 2019 Fall Meeting, AGU, San Francisco, CA, 9-13 Dec.

BAZARNIK J., MAJKA J., MCCLELLAND W.C., STRAUSS J.V. KOŚMIŃSKA K., PIEPJOHN K., ELVEVOLD S., CZUPYT C., MIKUŠ T. $2019 \mathrm{~b}-\mathrm{U}-\mathrm{Pb}$ zircon dating of metaigneous rocks from the Nordbreen Nappe of Svalbard's Ny-Friesland suggests their affinity to Northeast Greenland. Terra Nova, 31: 518-526.

BAZARNIK J., MAJKA J. 2021 - Raw data files and plots for the amphibolites and ultramafic rocks geochemistry from the West Ny-Friesland terrane (Eastern Svalbard Basement Province); https://osf.io/xetn5/ DALLMANN W.K., ANDRESEN A., BERGH S.G., MAHER H.D., OHTA Y. 1993 - Tertiary fold-and-thrust belt of Spitsbergen Svalbard Norsk Polarinstitutt Rapportserie, 128: 1-46.

DALLMANN W.K., ELVEVOLD S., MAJKA J., PIEPJOHN K. 2015 Chapter 8: tectonics and tectonothermal events. [W:] Dallmann W.K. (red). Geoscience Atlas of Svalbard. Nor Polarinst Rapportserie, Tromsø, 148: 175-220.

ELVEVOLD S., DALLMANNW.K. 2011 - Geological map of Svalbard 1:100 000, sheet C4G, Mosselhalvøya. Norsk Polarinstitutt Temakart 47. FAEHNRICH K., MAJKA J., SCHNEIDER D., MAZUR S., MANECKI M., ZIEMNIAK G., WALA V.T., STRAUSS J.V. 2020 - Geochronological constraints on Caledonian strike-slip displacement in Svalbard, with implications for the evolution of the Arctic. Terra Nova, 32: 290-299.

GEE D.G., TEBENKOV A.M. 2004 - Svalbard: a fragment of the Laurentian margin. [W:] Gee D.G., Pease V. (red). The Neoproterozoic Timanide Orogen of Eastern Baltica. Geol. Soc. London, Memoir, 30: 191-206.

HARLAND W.B. 1985 - Caledonide Svalbard. [W:] Gee D.G., Sturt B.A. (red). The Caledonide Orogen - Scandinavia and Related Areas. John Wiley and Sons, Chichester: 999-1016.

HARLAND W.B., HORSFIELD W.T. 1974 - West Spitsbergen orogen [W:] Spencer A.M. (red). Mesozoic-Cenozoic Orogenic Belts, Data for Orogenic Studies. Spec. Publ. Geol. Soc., 4: 747-755.

HELLMAN F.J., GEE D.G., JOHANSSON Å., WITT-NILSSON P. 1997 - Single-zircon $\mathrm{Pb}$ evaporation geochronology constrains basement-cover relationships in the lower Hecla Hoek Complex of northern Ny Friesland, Svalbard. Chem. Geol., 137: 117-134.

HELLMAN F.J., GEE D.G., WITT-NILSSON P. 2001 - Late Archean basement in the Bangenhuken Complex of the Nordbreen Nappe, western Ny-Friesland, Svalbard. Polar Res., 20: 49-59.

JOHANSSON Å., GEE D.G. 1999 - The late Palaeoproterozoic Eskolabreen granitoids of southern Ny Friesland, Svalbard Caledonides - geochemistry, age and origin. Geol. Fören. Stockholm Förh., 121: 113-126. JOHANSSON Å., GEE D.G., BJÖRKLUND L., WITT-NILSSON P. 1995 - Isotope studies of granitoids from the Bangenhuken Formation, Ny Friesland Caledonides, Svalbard. Geol. Mag., 132: 303-320.

MAJKA J., KOŚMIŃSKA K. 2017 - Magmatic and metamorphic events recorded within the Southwestern Basement Province of Svalbard. Arktos, 3: 5.

MAZUR S., CZERNY J., MAJKA J., MANECKI M., HOLM D.K., SMYRAK A., WYPYCH A. 2009 - A strike-slip terrane boundary in Wedel Jarlsberg Land, Svalbard, and its bearing on correlations of SW Spitsbergen with the Pearya terrane and Timanide belt. J. Geol. Soc., 166: 529-44.

MCCLELLAND W.C., VON GOSEN W., PIEPJOHN K. 2019 - Tonian and Silurian magmatism in Nordaustlandet: Svalbard's place in the Caledonian orogen. [W:] Piepjohn K., Strauss J.V., Reinhardt L., Mcclelland W.C. (red). Circum-Arctic Structural Events: Tectonic Evolution of the Arctic Margins and Trans-Arctic Links with Adjacent Orogens. Geol. Soc. Am. Sp. Pap., 541: 63-80.

MICHALSKI K., LEWANDOWSKI M., MANBY G. 2012 - New palaeomagnetic, petrographic and ${ }^{40} \mathrm{Ar} /{ }^{39} \mathrm{Ar}$ data to test palaeogeographic reconstructions of Caledonide Svalbard. Geol. Mag., 149: 696-721.

WITT-NILSSON P., GEE D.G., HELLMAN F.J. 1998 - Tectonostratigraphy of the Caledonian Atomfjella Antiform of northern Ny Friesland, Svalbard. Norsk Geologisk Tidskrift, 78: 67-80.

Praca wpłynęła do redakcji 6.04.2021 r.

Akceptowano do druku 7.05.2021 r. 


\section{Wstępna charakterystyka geochemiczna amfibolitów i skał ultramaficznych terranu West Ny-Friesland, północny Spitsbergen (patrz. str. 406)}

Preliminary geochemical characteristics of amphibolites and ultramafic rocks of the West Ny-Friesland Terrane, Northern Spitsbergen (see p. 406)

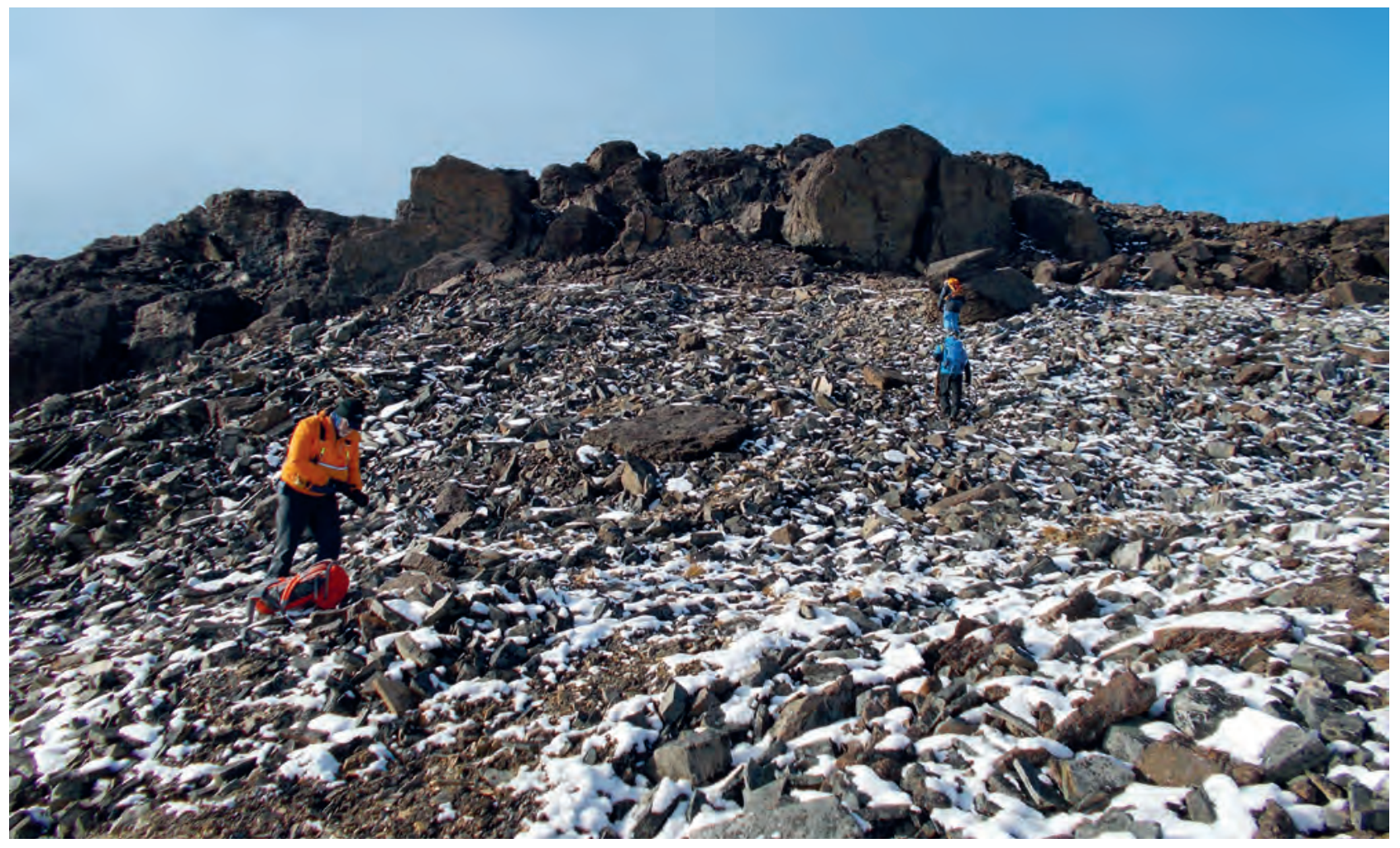

Ryc. 2. Linia skał ultramaficznych odsłaniających się na szczycie wzgórza (Polhemhøgdene, półwysep Ny-Friesland, północny Spitsbergen). Na pierwszym planie uczestnicy ekspedycji naukowej Circum Arctic Structural Events (CASE 18 - Mosselbukta 2015). Fot. J. Bazarnik

Fig. 2. The line of ultramafic rocks cropping out at the top of the hill (Polhemhøgdene, Ny-Friesland Peninsula, Northern Spitsbergen). In the foreground, members of the scientific expedition Circum Arctic Structural Events (CASE 18 - Mosselbukta 2015). Photo by J. Bazarnik

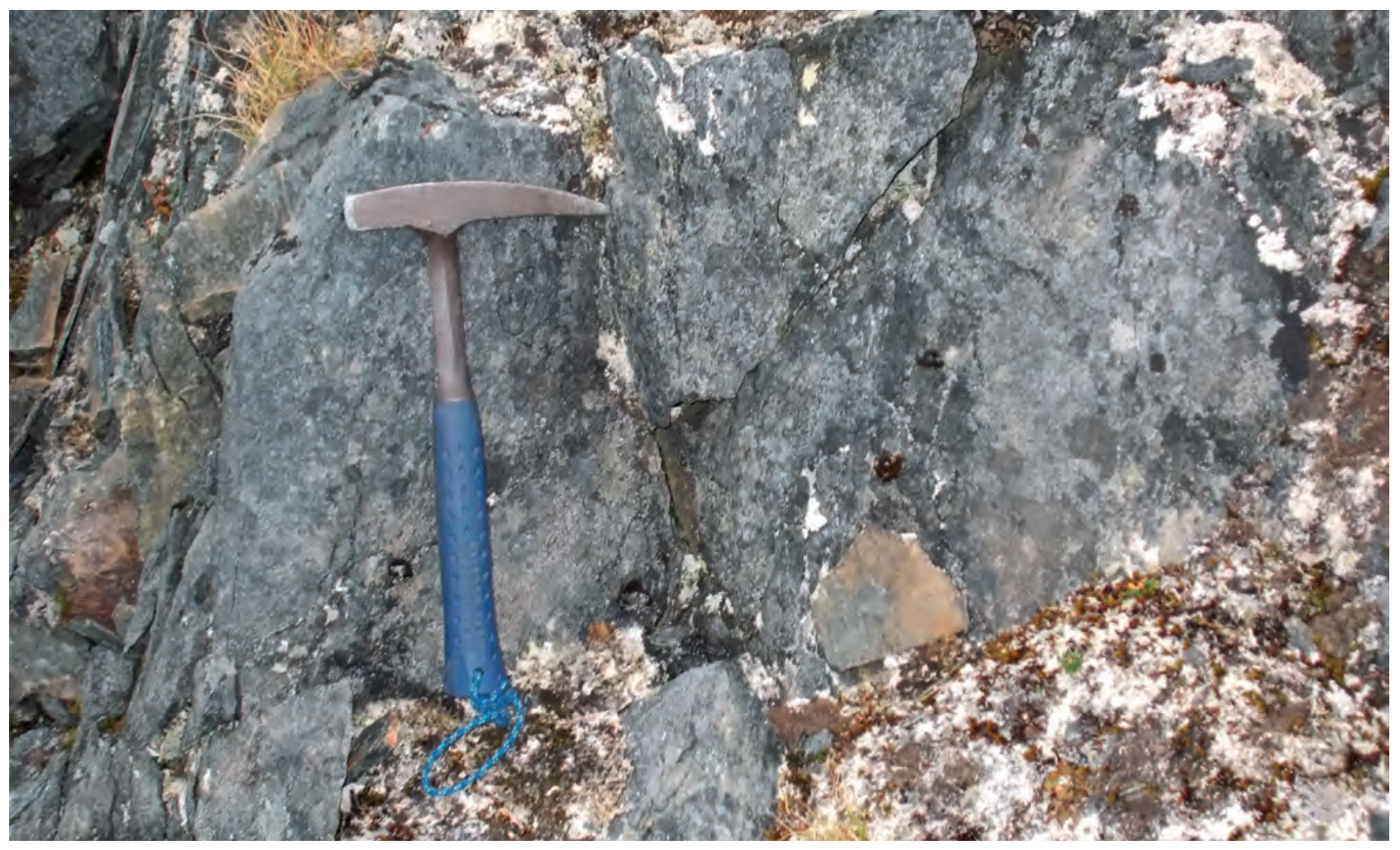

Ryc. 3. Odsłonięcie amfibolitów jednostki Polhem (równina Polhemflya, półwysep Ny-Friesland, północny Spitsbergen). Fot. J. Bazarnik Fig. 3. The outcrop of the Polhem unit amphibolite (Polhemflya, Ny-Friesland Peninsula, Northern Spitsbergen). Photo by J. Bazarnik 